\title{
Characterization of Molecular Interactions in Ethanol-Water Mixtures in Presence of Potassium Salts
}

\author{
S. D. DEOSARKAR ${ }^{\mathrm{a}^{*}}$, M. L. NARWADE ${ }^{\mathrm{b}}$ and V. V. PANDHARE
}

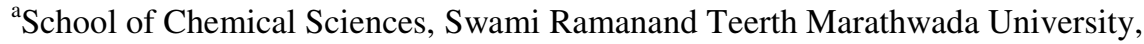
Nanded-431606 (MS), India

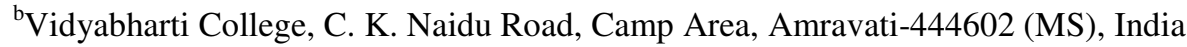

sandeo24@yahoo.co.in

Received 28 July 2012 / Accepted 4 September 2012

\begin{abstract}
Densities and viscosities of ternary mixtures of $\mathrm{KCl}, \mathrm{KBr}$ and $\mathrm{KI}$ in different percentage 10, 20,40 and $60 \% \mathrm{v} / \mathrm{v}$ ethanol-water for different concentrations of potassium salts were measured at $303.15 \mathrm{~K}$. Data obtained has been used to understand the ion-ion and ion-solvent interactions in solution. Effect of percentage of ethanol and concentrations of salts on strengthening or weakening of these interactions has been evaluated. Apparent molar volumes have also been estimated from density data of different systems. Ion-solvent interactions have been interpreted in terms of the partial molar volumes which were determined from Masson's relation.
\end{abstract}

Keywords: Densities, Viscosities, Apparent molar volumes, Ethanol-water mixture, Electrolyte solutions

\section{Introduction}

In electrolyte solutions ion-ion, ion-solvent and solvent-solvent interactions are present. These interactions can be fully understood from experimental studies like density, viscosity, refractive index, sound velocity etc. When electrolytes are added in solventmixtures, the existing structure of solvent mixtures affects and it changes to another structure. Variations in experimental and calculated properties give us an idea about these interactions. Molecular interactions in solution have been studied by many workers ${ }^{1-6}$. Apparent molar volumes of mixtures give an idea about solute-solvent interactions. Volumetric behaviors of electrolyte solutions provide information about various molecular interactions ${ }^{7-10}$. Concentration dependence of apparent molar volumes is used for determination of partial molar volumes.

In continuation with our previous work ${ }^{11-14}$ on study of molecular interactions, present paper reports experimental densities and viscosities and calculated apparent molar volumes of ternary mixtures of $\mathrm{KCl}, \mathrm{KBr}$ and $\mathrm{KI}$ in different percentage $(10,20,40$ and $60 \%) \mathrm{v} / \mathrm{v}$ ethanol-water for different concentrations of salts. Ion-ion and ion-solvent parameters are determined from Masson relation and discussed. 


\section{Experimental}

All glassware used were of Borosil make and precalibrated. Densities of different solutions were measured using density bottles (10 mL; Riviera make). Weighing was done on electronic balance (DENVER INSTRUMENT, SI-234; Max. $230 \mathrm{~g}$; d=0.1 mg; Denser instrument Germany). Solvent mixtures of ethanol-water (v/v) were prepared by mixing $10,20,40$ and $60 \mathrm{~mL}$ ethanol in water to make total $100 \mathrm{~mL}$ solution in calibrated volumetric flasks. Solutions of potassium salt were prepared in ethanol-water solvent mixture by dissolving accurately weighed salt in it. Viscosities of solutions were measured by using Ostwald's viscometer (Borosilicate Glass make) at constant temperature (303.15 K) by measuring flow times for ternary solutions and solvent mixtures. All calculations were performed on departmental computer using Microsoft office excel programme.

\section{Results and Discussion}

Table 1 and 2 represents various measured and derived properties of potassium salt solutions of different concentrations in ethanol-water mixtures of different compositions. Graphical representations of variation of densities and viscosities with concentration of potassium salts for different systems of ethanol-water are shown in Figure 1 and 2.

It can be seen from Figure 1 that densities of potassium salt solutions are increased with increase in concentration of salts for given percentage of ethanol-water mixture. Also it can be seen that densities are decreased largely with increase in percentage of ethanol in solution for approximately same concentration of salts. Variations in viscosities, as can be seen from Figure 2, indicates molecular interactions in solution.

Table 1. Densities and viscosities of potassium salt solutions of different concentrations in $10 \%, 20 \%, 40 \%$ and $60 \%$ v/v ethanol-water mixtures at $303.15 \mathrm{~K}$

\begin{tabular}{|c|c|c|c|c|c|c|c|c|}
\hline$\frac{C}{\mathrm{~mol} \cdot} \cdot$ & $\frac{\rho}{\mathrm{g} / \mathrm{cm}^{3}}$ & $\frac{\eta}{\mathrm{mPa} \mathrm{s}}$ & $\frac{C}{\mathrm{~mol} \cdot}$ & $\frac{\rho}{\mathrm{g} / \mathrm{cm}^{3}}$ & $\frac{\eta}{\mathrm{mPa} \mathrm{s}}$ & $\frac{C}{\mathrm{~mol} \cdot}$ & $\frac{\rho}{\mathrm{g} / \mathrm{cm}^{3}}$ & $\frac{\eta}{\mathrm{mPas}}$ \\
\hline & $\mathrm{KCl}$ & & $10 \%$ & $\begin{array}{l}\mathrm{KBr} \\
\text { ethanol }\end{array}$ & & & KI & \\
\hline 0.0298 & 0.9920 & 0.9084 & 0.0295 & 0.9923 & 0.9035 & 0.0294 & 0.9990 & 0.9148 \\
\hline 0.0578 & 0.9956 & 0.8737 & 0.0500 & 1.0030 & 0.9133 & 0.0575 & 1.0141 & 0.9287 \\
\hline 0.0822 & 1.0007 & 0.8782 & $\begin{array}{c}0.0899 \\
20 \%\end{array}$ & $\begin{array}{l}1.0129 \\
\text { ethanol }\end{array}$ & $\begin{array}{l}0.9223 \\
\text { vater }\end{array}$ & 0.0892 & 1.0286 & 0.9419 \\
\hline 0.0307 & 0.9764 & 1.1177 & 0.0288 & 0.9807 & 1.1430 & 0.0295 & 0.9869 & 1.1297 \\
\hline 0.0584 & 0.9822 & 1.1243 & 0.0598 & 0.9917 & 1.1197 & 0.0564 & 0.9993 & 1.1058 \\
\hline 0.0895 & 0.9816 & 1.1611 & $\begin{array}{c}0.0895 \\
40 \%\end{array}$ & $\begin{array}{l}1.0016 \\
\text { ethanol }\end{array}$ & $\begin{array}{l}1.1309 \\
\text { vater }\end{array}$ & 0.0881 & 1.0161 & 1.0856 \\
\hline 0.0299 & 0.9482 & 1.4834 & 0.0293 & 0.9547 & 1.5300 & 0.0295 & 0.9601 & 1.4654 \\
\hline 0.0601 & 0.9515 & 1.4885 & 0.0581 & 0.9638 & 1.5095 & 0.0592 & 0.9753 & 1.4421 \\
\hline 0.0888 & 0.9589 & 1.5733 & $\begin{array}{c}0.0897 \\
60 \%\end{array}$ & $\begin{array}{l}0.9742 \\
\text { ethanol }\end{array}$ & $\begin{array}{l}1.4548 \\
\text { vater }\end{array}$ & 0.0893 & 0.9882 & 1.5460 \\
\hline 0.0299 & 0.9073 & 1.5925 & 0.0287 & 0.9159 & 1.5679 & 0.0295 & 0.9225 & 1.6192 \\
\hline 0.0598 & 0.9121 & 1.5313 & 0.0588 & 0.9258 & 1.5848 & 0.0590 & 0.9356 & 1.6065 \\
\hline 0.0899 & 0.9156 & 1.6071 & 0.0897 & 0.9364 & 1.5689 & 0.0886 & 0.9520 & 1.5620 \\
\hline
\end{tabular}


Table 2. Apparent molar volumes of potassium salt solutions of different concentrations in $10 \%, 20 \%, 40 \%$ and $60 \% \mathrm{v} / \mathrm{v}$ ethanol-water mixtures at $303.15 \mathrm{~K}$

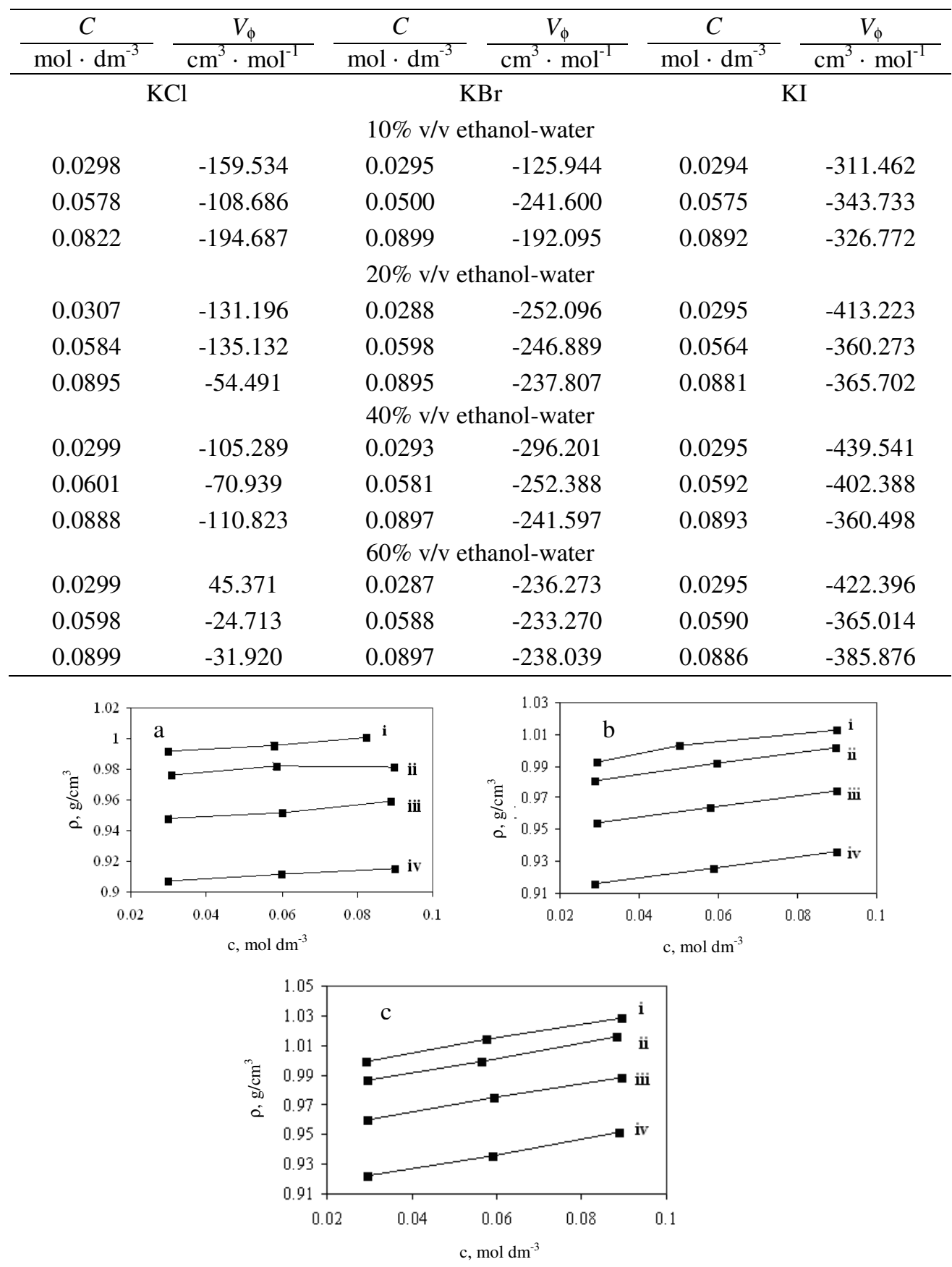

Figure 1. Variation of densities of different concentrations of a) $\mathrm{KCl}$; b) $\mathrm{KBr}$ and c) $\mathrm{KI}$ in (i) $10 \%$; (ii) $20 \%$; (iii) $40 \%$ and (iv) $60 \%$ v/v ethanol-water mixtures 

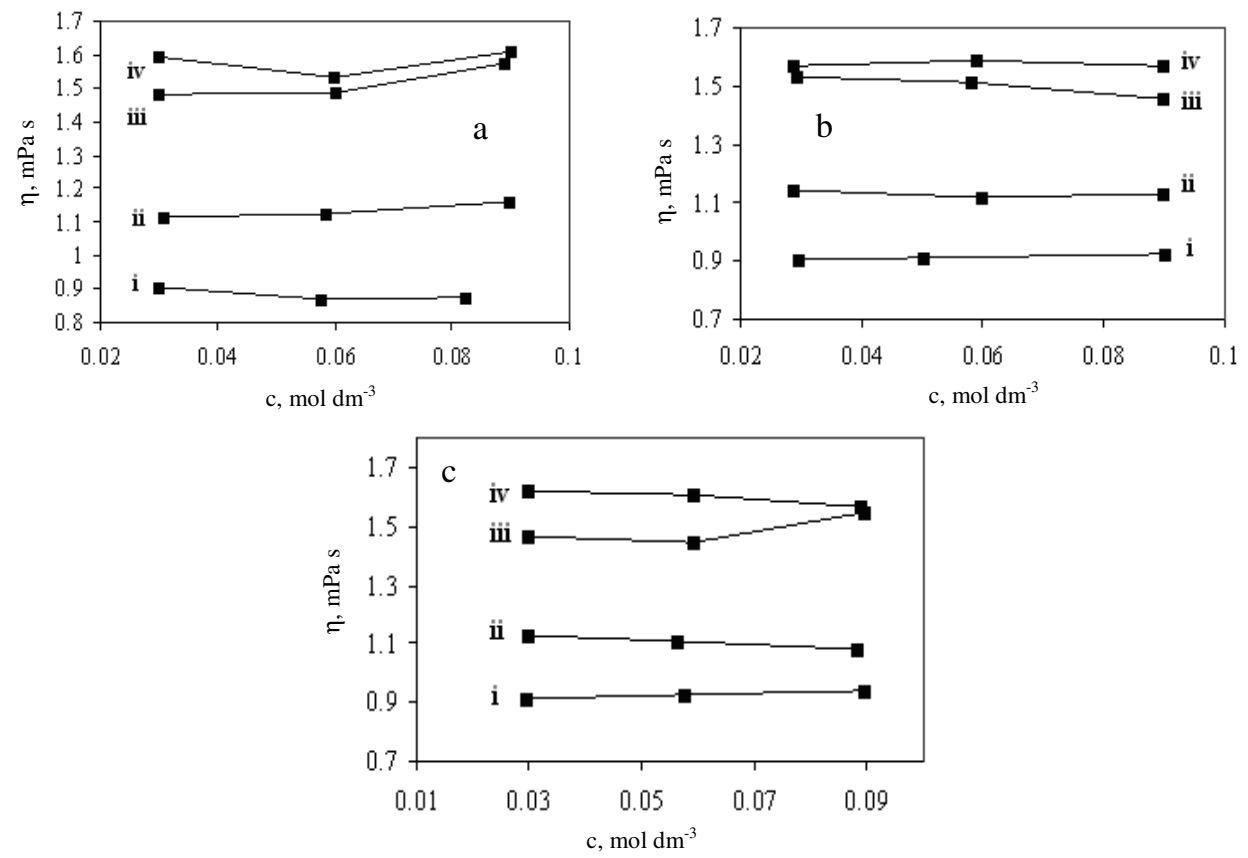

Figure 2. Variation of viscosities of different concentrations of a) $\mathrm{KCl}$; b) $\mathrm{KBr}$ and c) $\mathrm{KI}$ in (i) $10 \%$; (ii) $20 \%$; (iii) $40 \%$ and (iv) $60 \% \mathrm{v} / \mathrm{v}$ ethanol-water mixtures

Apparent molar volume $\left(V_{\phi}\right)$ is function of composition of solution and it is not constant even for a given temperature. Values of $V_{\phi}$ are calculated from measured densities of solutions $(\rho)$, density of given solvent mixture $\left(\rho_{0}\right)$, molecular weight of salt $(\mathbf{M})$ and molarity of salt solution (c) using following equation ${ }^{15-16}$.

$$
V_{\phi}=M / \rho_{0}-1000\left(\rho-\rho_{0}\right) / c \rho_{0}
$$

Calculated values of $V_{\phi}$ for all systems are reported in Table 2. It can be seen from the Table that values of $V_{\phi}$ are negative for all three salt systems of all compositions suggesting decrease in molar volume of solvent mixture on addition of small amount of solute which is attributed to the very weak electrostriction ${ }^{17}$ or weak solute-solvent interactions ${ }^{18}$. Potassium salts solutions in given $\%$ of ethanol-water has smaller volume than same $\%$ of ethanol-water mixtures.

Variation in apparent molar volume with square root of concentration of electrolyte is expressed by the Masson relation ${ }^{19-20}$ :

$$
V_{\phi}=V_{\phi}^{0}+S_{V} \sqrt{c}
$$

Apparent molar volume at infinite dilution is partial molar volume $\left(V_{\phi}^{0}\right)$ which is measure of ion-solvent interactions and $S_{\mathrm{v}}$ is measure of ion-ion interactions. $V_{\phi}^{0}$ and $S_{\mathrm{v}}$ has been read respectively as intercept and slope of the graph between $V_{\phi}$ and $\sqrt{ }_{c}$. Changes in $V_{\phi}$ with $\sqrt{ } \mathrm{c}$ are presented in Figure 3. $V_{\phi}$ and $S_{\mathrm{v}}$ values are reported in Table 3.

The solute-solvent interactions and structure of solute in solution can be reveled form thermodynamic quantity, the partial molar volume $\left(V_{\phi}^{0}\right)^{21}$ and $S_{\mathrm{v}}$, the ion-ion interaction parameter gives an idea about structure promoting or structure breaking ability of solute ${ }^{22}$. 

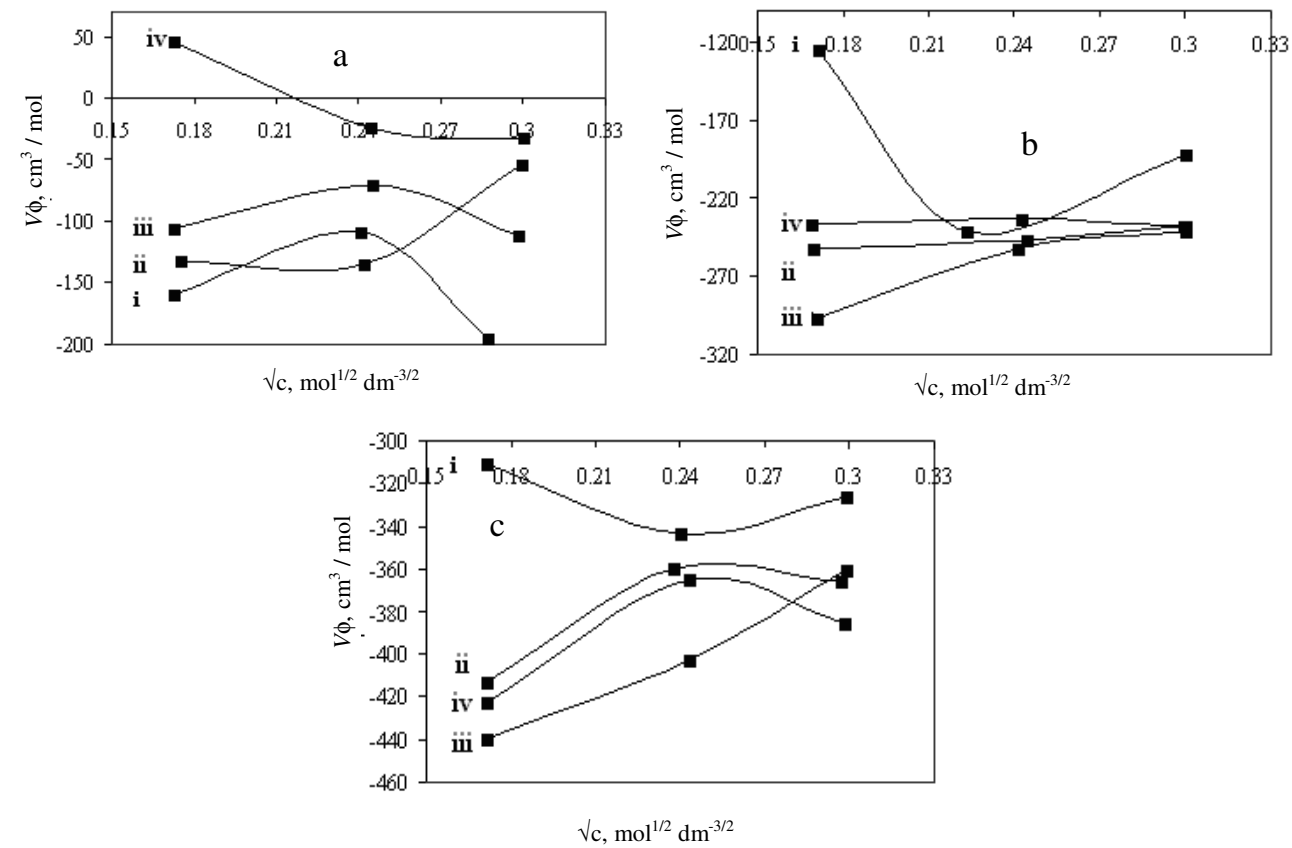

Figure 3. Variation of apparent molar volumes $\left(V_{\phi}\right)$ with $\sqrt{ }_{\mathrm{c}}$ of a) $\mathrm{KCl}$; b) $\mathrm{KBr}$ and c) $\mathrm{KI}$ in (i) $10 \%$; (ii) $20 \%$; (iii) $40 \%$ and (iv) $60 \% \mathrm{v} / \mathrm{v}$ ethanol-water mixtures

Table 3. Values of $S_{\mathrm{v}}$ and $V_{\phi}^{0}$ obtained from plot of $V_{\phi}$ versus $\sqrt{\mathrm{c}}_{\mathrm{C}}$

\begin{tabular}{ccccccc}
\hline \multirow{2}{*}{ System } & \multicolumn{2}{c}{$\mathrm{KCl}$} & \multicolumn{2}{c}{$\mathrm{KBr}$} & \multicolumn{2}{c}{$\mathrm{KI}$} \\
\cline { 2 - 7 } & $S_{\mathrm{v}}$ & $V_{\phi}^{0}$ & $S_{\mathrm{v}}$ & $V_{\phi}^{0}$ & $S_{\mathrm{v}}$ & $V_{\phi}^{0}$ \\
\hline $10 \%$ E-W solution & -230.03 & -100.65 & -429.61 & -86.991 & -129.66 & -296.64 \\
$20 \%$ E-W solution & 601.03 & -250.41 & 107.92 & -271.26 & 387.8 & -471.01 \\
$40 \%$ E-W solution & -13.297 & -92.91 & 432.04 & -365.89 & 617.55 & -547.77 \\
$60 \%$ E-W solution & -626.84 & 146.1 & -11.054 & -233.24 & 315.13 & -465.93 \\
\hline
\end{tabular}

Figure $4 \mathbf{c}$ gives complete information about two important interactions, ion-ion and ionsolvent. In this Figure parameters explaining these interactions are plotted with \% (v/v) of ethanol and therefore this Figure gives us information about variations in strengths of these interactions as solvent composition changes. We know that for the particular composition of the system, one type of interactions dominates over the other. It can be seen that for all three salt solutions for low ethanol percentage $(10 \% \mathrm{v} / \mathrm{v})$ both ion-ion and ion-solvent interactions are negligible, which means strong solvent-solvent interactions exists at this composition. One can assign this to the intermolecular hydrogen bonding between ethanol and water. Moving to the higher $\%$ of ethanol, it can be seen from Figure 4 that for $20 \% \mathrm{v} / \mathrm{v}$ ethanol, the ion-ion interactions $\left(S_{\mathrm{v}}\right)$ dominates and it continues till $60 \%$ ethanol for $\mathrm{KBr}$ and $\mathrm{KI}$ systems, this could be due to smaller interionic distance.

In case of $\mathrm{KCl}$ solutions ion-solvent interactions dominated over ion-solvent interactions for $40 \%$ and $60 \%$ of ethanol due to solvation of ions ${ }^{23}$. Comparison of values of $V_{\phi}$ and $S_{\mathrm{v}}$ indicates predominance of ion-ion interactions over ion-solvent interactions for higher $\%$ of ethanol ${ }^{24}$. 


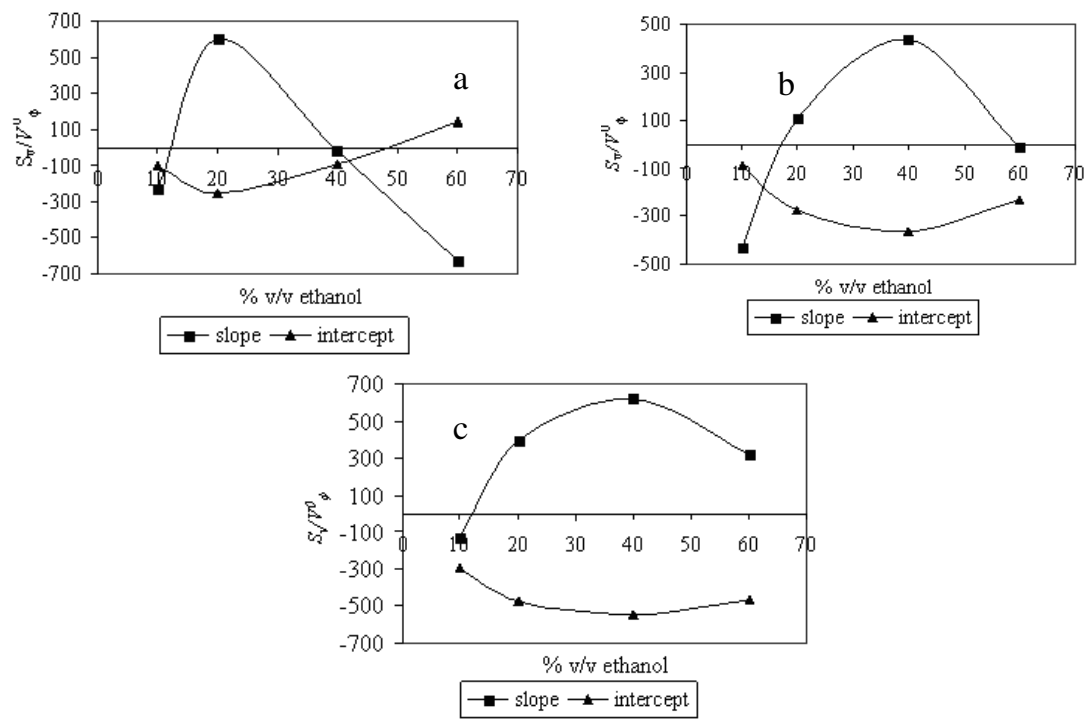

Figure 4. Variation of $S_{\mathrm{v}}$ (slope) and $V^{0} \phi$ (intercept) with \% (v/v) ethanol for a) $\mathrm{KCl}$; b) $\mathrm{KBr}$ and c) KI

\section{References}

1. Khan A R, Uddin F, Mukhtar M and Saeed R, Front Chem China, 2011, 6, 113-119.

2. Deosarkar S D, Puyad A L and Kalyankar T M, Rus J Phy Chem A, 2012, 86(5), 775.

3. Khan A R, Uddin F and Mukhtar M, J Chem Eng Data, 2007, 52(5), 1548-1551.

4. Roy M N, Sinha B and Dakua V K, J Chem Eng Data, 2006, 51(2), 590-594.

5. $\quad$ Roy M N and Sinha B, J Mol Liq., 2007, 133(1-3), 89-99.

6. Shigendo Akita and Hiroshi Takeuchi, J Chem Eng Data, 1992, 37(3), 303-306.

7. Klofutar C, Horvat J and Rudan-Tasic D, Acta Chim Slov., 2006, 53(3), 274-283.

8. Pal A and Chauhan N, J Solution Chem., 2010, 39(11), 1636-1652.

9. Calvar N, Gonz'alez B, Dom'́nguez A and Tojo J, J Solution Chem., 2006, 35(9), 1217.

10. Choudhary D and Aswar A, J Therm Anal Calorim., 2012, 107, 21.

11. Deosarkar S D, Narwade M L and Thakare V J, Int J Chem Sci., 2009, 7, 1263.

12. Deosarkar S D and Narwade M L, J Chemical Biological and Physical Science, Sec A, 2012, 2(3), 1200-1205.

13. Deosarkar S D and Narwade M L, Rasayan J Chem., 2010, 3(1), 55-59.

14. Deosarkar S D, Jahagirdar H G, Wagh S D and Patil P P, J Chemical Biological and Physical Science, Sec A, 2012, 2(2), 654-660.

15. Kabiraz D C, Biswas T K and Huque M E, Monatsh Chem., 2010, 141, 1063-1068.

16. Roy M N, Das R K and Bhattacharjee A, Russ J Phy Chem A, 2010, 84, 2201.

17. Nikam P and Hiray A R, Indian J Pure Appl Phys., 1991, 29, 601.

18. Gajera R, Bhalodia R and Baluja S, Russ J Phy Chem A, 2010, 84, 766,

19. Masson D O, Philosophical Magazine, 1929, 8, 218.

20. Rajwade B R P and Pande R, J Chem Eng Data, 2008, 53(7), 1458-1461.

21. Imai T, Condens Matter Phys., 2007, 10, 343-362, DOI:10.5488/CMP.10.3.343.

22. Wen W Y and Saito S, J Phys Chem., 1964, 68, 2639.

23. Roy M N, Sinha B, Dey R, and Sinha A, Int J Thermophys, 2005, 26(5), 1549-1563.

24. Roy M N, Sah R S, Pradhan P P and Roy P K, Russ J Phy Chem A, 2009, 83, 1887. 